\title{
Drug-Induced Parkinsonism and Neuroleptic Malignant Syndrome: A Case Report
}

\author{
Alexey A. Tappakhov, $\mathrm{PhD}^{1,2^{*}}$; Tatiana E. Popova, $\mathrm{PhD}, \mathrm{ScD}^{1,2}$; Yulia I. Khabarova, $\mathrm{PhD}^{2}$; \\ Maria V. Yakovleva, $\mathrm{PhD}^{2}$; Alina E. Adamova ${ }^{2}$; Tatiana G. Govorova ${ }^{1}$; Michil E. Andreev ${ }^{1}$ \\ ${ }^{1}$ M.K. Ammosov North-Eastern Federal University \\ ${ }^{2}$ Yakut Science Center of Complex Medical Problems \\ Yakutsk, the Republic of Sakha (Yakutia), Russia
}

\begin{abstract}
The article presents a clinical case of neuroleptic malignant syndrome (NMS) and drug-induced parkinsonism after a single dose of thiorizadine, and discusses the issues of differential diagnosis and treatment methods. A 57-year-old patient with long-term remission of schizophrenia due to insomnia was prescribed thiorizadine. After a single dose, symptoms of parkinsonism in the form of hypokinesia, muscle rigidity and bradyphrenia developed and began to progress. Three weeks later NMS developed, and treatment was carried out in the intensive care unit. When signs of parkinsonism persisted, she was hospitalized in the neurological department. Regression of symptoms occurred by her taking amantadine sulfate. (International Journal of Biomedicine. 2020;10(2):174-177.)
\end{abstract}

Key Words: neuroleptic malignant syndrome $\bullet$ drug-induced parkinsonism $\bullet$ antipsychotic drugs $\bullet$ Parkinson’s disease

\section{Abbreviations}

DIP, drug-induced parkinsonism; NMS, neuroleptic malignant syndrome; MoCA, Montreal Cognitive Assessment; MMSE, Mini-Mental State Examination

\section{Introduction}

The synthesis of antipsychotics was a cardinal event of the 20th century and became a new stage in the development of psychopharmacotherapy and the treatment of mental disorders. ${ }^{(1)}$ However, it was soon discovered that these drugs could have unfortunate side effects. In 1954, two articles were published that described the development of drug-induced parkinsonism (DIP) in patients treated with reserpine and chlorpromazine. ${ }^{(2,3)}$ Currently, DIP is observed in $10 \%-25 \%$ of patients who are treated with antipsychotics, and is one of the common causes of secondary parkinsonism. ${ }^{(4)}$ Rarer causes of DIP include prokinetics (domperidone, metoclopramide), calcium channel blockers (cinnarizine, diltiazem, verapamil), central sympatholytics (a-methyldopa), drugs that deplete

*Corresponding author: Alexey A. Tappakhov, PhD, Ass. Professor of the Department of Neurology and Psychiatry of Medical Institute, M.K. Ammosov North-Eastern Federal University, Yakutsk, Russia.E-mail: dralex89@mail.ru monoamine reserves (reserpine, tetrabenazine) serotonergic drugs and antidepressants (amitriptyline, imipramine). ${ }^{(5,6)}$

The Diagnostic and Statistical Manual of Mental Disorders, fifth edition (DSM-V), defines DIP as the presence of a resting tremor, muscular rigidity, akinesia, or bradykinesia, developing within a few weeks of starting or raising the dosage of a medication (typically a neuroleptic) or after reducing the dosage of an antiparkinsonian agent. ${ }^{(7)}$ Therefore, in contrast to the diagnostic criteria for Parkinson's disease, slowness and impoverishment of movements are not obligatory signs for verifying DIP. Most cases with antipsychotics develop within 3 months, but in the case of calcium channel blockers, the drug exposure can be up to 12 months. ${ }^{(8)}$ Despite the lack of consensus on the time of regression of parkinsonism symptoms with a dose reduction or complete withdrawal of the causative drug, most often this time is 6 months. ${ }^{(5)}$ In one study, the improvement time ranged from 2 to 19 months (average 10 months). ${ }^{(9)}$

A rarer complication of antipsychotic drug therapy is neuroleptic malignant syndrome (NMS), which is manifested 
by muscle rigidity, impaired consciousness, hyperpyrexia, and autonomic dysfunction. ${ }^{(10)}$ NMS is an urgent condition, accompanied by an impairment of vital functions, and can lead to death. ${ }^{(11)}$ Typical antipsychotics such as haloperidol and chlorpromazine are most commonly associated with NMS; however, in some cases atypical antipsychotics, neuroleptics, prokinetics, and lithium drugs have been described. ${ }^{(12)}$

In this article, we present our own clinical observation of a patient with prolonged remission of schizophrenia, who, after a single dose of thiorizadine, developed DIP and NMS.

\section{Case presentation}

A 57-year-old woman, an economist, with a prolonged remission of schizophrenia. At the age of 32, she developed insomnia, anxiety and hypothymia. It seemed to her that her colleagues were accusing her of the economic crisis in Russia. Then she began to hallucinate and heard "voices" of the accusatory content, as a result of which she was hospitalized in a psychiatric hospital. In the clinical picture of the psychotic state, depressive-paranoid symptoms and catatonia were detected. She was treated with antipsychotics and insulin coma sessions. A diagnosis of schizophrenia was established. There were no more exacerbations of the disease.

At the age of 46, the patient developed an ischemic stroke with motor aphasia and right-sided hemiparesis with full recovery. Three months before contacting us, she developed insomnia, and also stopped eating. Relatives associated these symptoms with stress. After 4 days, due to continued insomnia, the doctor prescribed thiorizadine and amitriptyline. The patient took the medicine. Her relatives reported that she could take several tablets of thiorizadine. The next morning, she became inhibited, could not stand up, talk, or look "at one point." She was hospitalized in the therapeutic department. On examination, symptoms of parkinsonism were identified: slowness of movements, muscle rigidity, microbasia, "maskface," and hypophony. On Day 6 of hospitalization, in the daytime, she began to talk better and motor activity increased. However, in the evening her condition deteriorated.

On Day 8 of treatment, slowness of movements and muscle rigidity significantly increased, she began to speak beside the point, and a sub-febrile temperature appeared. Cerebrospinal fluid was without pathology. Sinus tachycardia was detected by an ECG. On Day 15 of treatment, hyperthermia $\left(>40^{\circ} \mathrm{C}\right)$, severe muscle rigidity, paroxysmal tachycardia, and stupor developed. A blood test revealed an increase in the levels of urea $(15.1 \mathrm{mmol} / \mathrm{l})$, creatinine $(144.9 \mathrm{mmol} / \mathrm{l})$, creatine kinase $(3466 \mathrm{U} / 1)$, and leukocytes $\left(14.8 \times 10^{9} / 1\right)$. An MRI of the brain showed no signs of stroke or inflammation. We conducted detoxification therapy and a single session of plasmapheresis. During treatment, consciousness recovered, muscle rigidity decreased, and autonomic disorders were stopped; creatinine kinase decreased to 394U/1. However, symptoms of parkinsonism persisted.

She was discharged from the hospital on Day 40 from the time of hospitalization.

The patient retained slowness of movement, muscle rigidity, stoop, slowness of thinking, and impaired walking (she could only move with support). Relatives were also worried about the lack of emotions and motivation ("she refuses everything, does not want to do anything"). As relatives noted, the patient periodically experienced shortterm episodes of some improvement, during which physical activity increased, she could independently move around the apartment, and more fully and clearly answer questions.

Neurological examination revealed a slowing of the eye saccades, hypomimia, bradylalia, muscle rigidity (the "lead tube" phenomenon), axial muscle rigidity, no paresis and no tremor, severe symmetrical hypokinesia, microbasia, and a need for support to walk. On 3 parts of the UPDRS scale - 46 points.

Qualitative examination of cognitive functions was not possible. The patient revealed bradyphrenia, was confused about the anamnestic information, and could confuse dates and events; but she correctly orientated herself and recognized her relatives.

The patient was hospitalized in the neurological department, where treatment with amantadine sulfate (50 mg 3 times a day) was started. The dose of the medicine was increased to $100 \mathrm{mg} 3$ times a day. During the week, symptoms of parkinsonism significantly decreased (3 part of UPDRS - 19 points). However, the patient developed anxiety, hypotension, bradyphrenia, apathy, and memory problems. The MoCA and MMSE points were 21/20. The geriatric depression scale revealed deep depression (26 points). Venlafaxine was added at a dose of $37.5 \mathrm{mg} 2$ times a day with further titration. The patient was referred to a psychiatrist for observation.

\section{Discussion}

The development of extrapyramidal neuroleptic syndromes, including DIP and NMS, is associated with inhibition of dopaminergic transmission. ${ }^{(13)}$ The likelihood of parkinsonism developing in antipsychotic therapy is directly proportional to the drugs' ability to block postsynaptic D2dopamine receptors and inversely proportional to their ability to block M-cholinergic receptors and serotonin 5-HT2 receptors. ${ }^{(4)}$ Therefore, typical antipsychotics (for example, haloperidol, chlorpromazine, thiorizadine, etc.) have a high risk of developing DIP, because they have a high ability to inhibit dopaminergic activity but have a weak ability to reduce cholinergic and serotonergic systems. Atypical antipsychotics have a lower risk; the main effect is due to the blockade of the D4-dopamine receptors in the limbic system and serotonin receptors in the striatum (clozapine, quetiapine, olanzapine, etc.). (5) It has been established that the development of parkinsonism requires the blockade of more than $75 \%$ of dopamine receptors, while the antipsychotic effect is achieved when $50 \%-75 \%$ of the receptors are blocked. ${ }^{(6)}$

The risk factors for DIP include old age, because as the person ages, the amount of dopamine decreases and sensitivity to antipsychotics increases. ${ }^{(8,9)}$ In addition, patients with cognitive impairment are more prone to side effects of antipsychotics, which is associated with initially low cholinergic activity. ${ }^{(14)}$ Other risk factors include female gender, the presence of extrapyramidal disorders, organic 
brain damage and brain atrophy, HIV infection, and a family history of parkinsonism. ${ }^{(4-6,13)}$

A feature of drug parkinsonism is that motor disorders are potentially reversible (usually within 6 months). However, symptoms can persist and even worsen in $30 \%$ of cases after discontinuation or dose adjustment of the causative drug. ${ }^{(15)}$ A large study involving 2991 patients showed a 3.2-fold increase in the risk of Parkinson's disease with antipsychotics, and in 30\% of cases signs of the disease developed during antipsychotic therapy. ${ }^{(16)}$ Symmetry of symptoms, the predominance of postural tremor, the presence of oromandibular dyskinesias, and a variable (often negative) response to levodopa are associated with DIP. ${ }^{(5,17)}$ Parkinson's disease, in contrast, is indicated by previous hyposmia and rapid eye movement (REM) sleep behavior disorder. ${ }^{(6,18)}$ Positron emission tomography can help in the differential diagnosis of Parkinson's disease and DIP. ${ }^{(19)}$

The treatment of DIP involves the abolition of the causative drug. If there is a need to continue antipsychotic therapy, atypical antipsychotics (usually clozapine or quetiapine) can be prescribed. Another group of drugs is anticholinergics, the mechanism of action of which is associated with the selective blocking of M1-cholinergic receptors in the basal ganglia. NMDA-receptors antagonists (amantadines) reduce the level of glutamate and acetylcholine in the striatum, as well as increase dopamine synthesis in presynaptic terminals, and inhibit the reuptake of dopamine from the synaptic cleft. ${ }^{(4,5,13,20)}$

The development of NMS is associated with a blockade of D2-dopamine receptors, not only in the basal ganglia, but also in the hypothalamus. ${ }^{(10)}$ However, according to the pharmacological monitoring in Canada, the number of reports of NMS with atypical antipsychotics (in particular, clozapine) is higher than NMS with typical antipsychotics. ${ }^{(21)}$ Similar results were obtained when analyzing the database of the Australian Advisory Committee on Drug Side Effects. ${ }^{(22)}$ Therefore, the leading role in NMS cannot belong to dopamine mechanisms but may be associated with dysfunction of the serotonergic and cholinergic systems. ${ }^{(23)}$ This conclusion is also supported by the clinical similarity of NMS to serotonin syndrome. $^{(12)}$

NMS often develops in the initial stage of treatment with antipsychotics or with an increase in their dose. The risk increases with polypharmacy, especially while taking antidepressants and antiparkinsonian drugs. ${ }^{(24)}$ Other factors associated with the risk of NMS are immobility, dehydration, high fever, intercurrent infections, and a family history of catatonia. $^{(21,25)}$

The differential diagnosis of NMS is presented in Table 1.

NMS is an urgent condition. Of primary importance is the cessation of the causal antipsychotics. Supportive therapy includes antipyretic methods, correction of metabolic disorders, prevention of respiratory and cardiovascular failure. Recent reviews recommend the administration of a dopamine receptor agonist, bromocriptine. Benzodiazepines are recommended to reduce muscle stiffness and reduce rhabdomyolysis. Electroconvulsive therapy can be used in refractory cases. ${ }^{(11,13,21)}$
Table 1.

The differential diagnosis of NMS

\begin{tabular}{|l|l|}
\hline Urgent conditions & \multicolumn{1}{|c|}{ Key diagnostic features } \\
\hline NMS & $\begin{array}{l}\text { Hyperthermia over } 38^{\circ} \mathrm{C} \\
\text { Muscle rigidity } \\
\text { Change in consciousness } \\
\text { Autonomic disorders } \\
\text { Increased creatine kinase in blood } \\
\text { Increased white blood cell count }\end{array}$ \\
\hline Serotonin syndrome & $\begin{array}{l}\text { The acute onset } \\
\text { Change in consciousness } \\
\text { Signs of central nervous system hyper- } \\
\text { myoclonus, akathisia), hyperreflexia, } \\
\text { clonus, convulsions } \\
\text { Autonomic disorders (often mydriasis, } \\
\text { tachycardia) } \\
\text { Mild or moderate muscle rigidity without } \\
\text { increased creatine kinase in blood }\end{array}$ \\
\hline $\begin{array}{l}\text { Febrile } \\
\text { schizophrenia } \\
\text { ("lethal catatonia") }\end{array}$ & $\begin{array}{l}\text { Symptoms mimics NMS! } \\
\text { No causal relationship with antipsychotics } \\
\text { Oneiroid syndrome }\end{array}$ \\
\hline $\begin{array}{l}\text { Symptoms mimics NMS! } \\
\text { It develops in patients with Parkinson's } \\
\text { disease with intercurrent infections, } \\
\text { exacerbation of chronic diseases, or abrupt } \\
\text { cancellation of antiparkinsonian therapy }\end{array}$ \\
\hline akis
\end{tabular}

In the clinical case described here, the development of NMS as a result of a single dose of the typical antipsychotic thioridazine is an occurrence of interest; it is probably associated with the mechanisms of drug idiosyncrasy. ${ }^{(23)}$ The absence of a previous history of parkinsonism reduces the likelihood of a significant decrease in dopamine-synthesizing neurons, which could predispose the patient to a high sensitivity to antipsychotics. A history of a catatonic state in schizophrenia may indicate a genetic "hyper" sensitivity to antipsychotics, although we cannot be completely sure which drug from this group was used. It is likely that there are genetic characteristics that affect the metabolism of antipsychotics and can predispose a patient to the development of NMS. For example, under discussion is the clinical significance of the genetic polymorphism of cytochrome P450 (CYP) 2D6 in the metabolism of haloperidol and its effect on the risk of NMS developing. ${ }^{(26)}$

In the present case, the persistence of parkinsonism symptoms after NMS, and the presence of fluctuations with episodes of improvement, could suggest the onset of Parkinson's disease or dementia with Levi bodies. However, the absence of any previous non-motor symptoms, the symmetry of symptoms, and a positive response to amantadine indicate DIP.

\section{Competing Interests}

The authors declare that they have no competing interests. 


\section{Sources of Funding}

This work was supported by the Grant of the President of the Russian Federation for State Support of Young Scientists and Leading Scientific Schools (MK-2254.2020.7).

\section{References}

1. Danilov DS. [Benzamide neuroleptics in the practice of a psychiatrist, a neurologist, and an internist at the present development stage of psychopharmacology (by the example of sulpiride)]. Nevrologiya, Neyropsikhiatriya, Psikhosomatika. 2012;4(3):77-85. doi: 10.14412/2074-2711-2012-410. [Article in Russian].

2. Steck H. [Extrapyramidal and diencephalic syndrome in the course of largactil and serpasil treatments]. Ann Med Psychol (Paris). 1954;112(25):737-44. [Article in French].

3. Bergouignan M, Regnier G. [Reversible parkinsonism in the course of largactil therapy of vomiting in pregnancy]. J Med Bord. 1954;131(7):678-679. [Article in French].

4. Levin OS, Shindryaeva NN, Anikina MA. [Drug-induces parkinsonism]. Zh Nevrol Psikhiatr Im S S Korsakova. 2012;112(8):76-81. [Article in Russian].

5. Blanchet P, Kivenko V. Drug-induced parkinsonism: diagnosis and management. J Park Restless Legs Syndr. 2016;6:83-91. doi: 10.2147/JPRLS.S99197.

6. Nodel MR. [Drug-induced parkinsonism: risk minimization options] Nervnye Bolezni. 2015;3:18-22. [Article in Russian].

7. American Psychiatric Association. Diagnostic and Statistical Manual of Mental Disorders, Fifth Edition; 2013. doi: 10.1176/appi.books.9780890425596.

8. Bondon-Guitton E, Perez-Lloret S, Bagheri H, Brefel C, Rascol O, Montastruc J-L. Drug-induced parkinsonism: a review of 17 years' experience in a regional pharmacovigilance center in France. Mov Disord. 2011;26(12):2226-2231. doi: 10.1002/mds.23828.

9. Esper CD, Factor SA. Failure of recognition of drug-induced parkinsonism in the elderly. Mov Disord. 2008;23(3):401-404. doi: 10.1002/mds.21854.

10. Malin DI. [Malignant antipsychotic syndrome: diagnosis and therapy]. Sovremennaya Terapiya Psikhicheskikh Rasstroystv. 2016;2:2-9. doi: 10.21265/PSYPH.2016.0.1757. [Article in Russian].

11. Pileggi DJ, Cook AM. Neuroleptic Malignant Syndrome. Ann Pharmacother. 2016;50(11):973-981. doi: $10.1177 / 1060028016657553$.

12. Duma SR, Fung VS. Drug-induced movement disorders. Aust Prescr. 2019;42(2):56-61. doi: 10.18773/ austprescr.2019.014.

13. Fedorova NV, Vetokhina TN. [Diagnosis and treatment of antipsychotic extrapyramidal syndromes]. Psikhicheskie Rasstroystva v Obshchey Meditsine. 2009;3:18-24. [Article in Russian].

14. Thanvi B, Treadwell S. Drug induced parkinsonism: a common cause of parkinsonism in older people. Postgrad Med J. 2009;85(1004):322-326. doi: 10.1136/pgmj.2008.073312.
15. Brigo F, Erro R, Marangi A, Bhatia K, Tinazzi M. Differentiating drug-induced parkinsonism from Parkinson's disease: An update on non-motor symptoms and investigations. Parkinsonism Relat Disord. 2014;20(8):808-814. doi: 10.1016/j.parkreldis.2014.05.011.

16. Foubert-Samier A, Helmer C, Perez F, Le Goff M, Auriacombe S, Elbaz A, et al. Past exposure to neuroleptic drugs and risk of Parkinson disease in an elderly cohort. Neurology. 2012;79(15):1615-1621. doi: 10.1212/ WNL.0b013e31826e25ce.

17. López-Sendón JL, Mena MA, de Yébenes JG. Druginduced parkinsonism in the elderly: incidence, management and prevention. Drugs Aging. 2012;29(2):105-118. doi: 10.2165/11598540-000000000-00000.

18. Kim JS, Oh YS, Kim YI, Yang DW, Chung YA, You IR, et al. Combined use of 123I-metaiodobenzylguanidine (MIBG) scintigraphy and dopamine transporter (DAT) positron emission tomography (PET) predicts prognosis in drug-induced Parkinsonism (DIP): a 2-year follow-up study. Arch Gerontol Geriatr. 2013;56(1):124-128. doi: 10.1016/j. archger.2012.05.001.

19. Vlaar AMM, de Nijs T, Kessels AGH, Vreeling FW, Winogrodzka A, Mess WH, et al. Diagnostic value of 123I-ioflupane and 123I-iodobenzamide SPECT scans in 248 patients with parkinsonian syndromes. Eur Neurol. 2008;59(5):258-266. doi: 10.1159/000115640.

20. Anikeev LM, Anikeeva LV. ]The experience of using PKMerz in antipsychotic syndrome in a psychiatric hospital]. Effektivnaya Farmakoterapiya. 2011;19:32. [Article in Russian].

21. Tse L, Barr A, Scarapicchia V, Vila-Rodriguez F. Neuroleptic Malignant Syndrome: A Review from a Clinically Oriented Perspective. Curr Neuropharmacol. 2015;13(3):395406. doi: 10.2174/1570159x1399915042411334.

22. Trollor JN, Chen X, Chitty K, Sachdev PS. Comparison of neuroleptic malignant syndrome induced by first- and secondgeneration antipsychotics. Br J Psychiatry. 2012;201(1):5256. doi: 10.1192/bjp.bp.111.105189.

23. Barylnik YuB, Filippova NV, Antonova AA, Guseva MA, Magomedova MS. [Malignant neuroleptic syndrome in the treatment of atypical antipsychotics (review)]. Psikhiatriya i psikhofarmakoterapiya im P.B Gannushkina. 2017; 2: 24-26. [Article in Russian].

24. Su YP, Chang CK, Hayes RD, Harrison S, Lee W, Broadbent M, et al. Retrospective chart review on exposure to psychotropic medications associated with neuroleptic malignant syndrome. Acta Psychiatr Scand. 2014;130(1):5260. doi: $10.1111 /$ acps. 12222 .

25. Viejo LF, Morales V, Puñal P, Pérez JL, Sancho RA. Risk factors in neuroleptic malignant syndrome. A case-control study. Acta Psychiatr Scand. 2003; 107(1): 45-49. Doi: 10.1034/j.1600-0447.2003.02385.x.

26. Arkhipov VV, Berdnikova NG, Zhuravleva MV, Kukes VG. [A retrospective analysis of a case of an adverse reaction - a malignant neuroleptic syndrome in the use of haloperidol]. Bezopasnost' i risk farmakoterapii. 2015; 2: 30-39. [Article in Russian]. 